\title{
Precursory tilt changes associated with a phreatic eruption of the Hakone volcano and the corresponding source model
}

\author{
Ryou Honda ${ }^{* *} \mathbb{0}$, Yohei Yukutake ${ }^{1}$, Yuichi Morita ${ }^{2}$, Shin'ichi Sakai ${ }^{2}$, Kazuhiro Itadera ${ }^{1}$ and Kazuya Kokubo ${ }^{3}$
}

\begin{abstract}
The 2015 unrest of the Hakone volcano in Japan, which began on April 26, generated earthquake swarms accompanied by long-term deformation. The earthquake swarm activity reached its maximum in mid-May and gradually calmed down; however, it increased again on the morning of June 29, 2015. Simultaneously with the earthquake increase, rapid tilt changes started $10 \mathrm{~s}$ before 07:33 (JST) and they lasted for approximately $2 \mathrm{~min}$. The rapid tilt changes likely reflected opening of a shallow crack that was formed near the eruption center prior to the phreatic eruption on that day. In this study, we modeled the pressure source beneath the eruption center based on static tilt changes determined using both tilt meters and broadband seismometers. In the best-fit model, the source depth was $854 \mathrm{~m}$ above sea level, and its orientation (N316 ${ }^{\circ} \mathrm{E}$ ) agreed with the direction of maximum compression estimated based on focal mechanism and S-wave splitting data. The extent of the crack opening was estimated to be $4.6 \mathrm{~cm}$, while the volume change was approximately $1.6 \times 10^{5} \mathrm{~m}^{3}$. The top of the crack reached to approximately $150 \mathrm{~m}$ below the eruption center. Because the crack was too thin to be penetrated by magma, the crack opening was attributed to the intrusion of hydrothermal water. This intrusion of hydrothermal water may have triggered the phreatic eruption. Reverse polarity motion with respect to that expected from crack opening was recognized in $1 \mathrm{~Hz}$ tilt records during the first $20 \mathrm{~s}$ of the intrusion of hydrothermal water. This motion, not the subsidence of volcanic edifice, was responsible for the observed displacement.
\end{abstract}

Keywords: Hakone volcano, Broadband seismogram, Tilt change, Pressure source model

\section{Introduction}

The Hakone volcano is an active volcano in central Japan (Fig. 1). The observation network of the Hot Springs Research Institute (HSRI) in Kanagawa Prefecture has repeatedly detected earthquake swarms associated with the Hakone volcano (Mannen 2003; Yukutake et al. 2010; Honda et al. 2011). Despite the repeated observation of the inflation of the mountain edifice accompanying the earthquake swarm activity (Daita et al. 2009; Yukutake et al. 2016), no eruptions have been detected since the modern observation network was constructed in the 1960s. The largest event documented at Hakone since the

\footnotetext{
*Correspondence: ryou@onken.odawara.kanagawa.jp

${ }^{1}$ Hot Springs Research Institute of Kanagawa Prefectural Government,

586 Iriuda, Odawara, Kanagawa 250-0031, Japan

Full list of author information is available at the end of the article
}

establishment of the observation network was the 2015 unrest, which began on April 26, 2015. After this date, the daily number of earthquakes first increased rapidly and then decreased slowly after the most violent day of activity (May 15, 2015) when 955 earthquakes $(M \geq 0)$ were detected (Fig. 2, Mannen et al. 2018).

During the 2015 unrest, borehole tilt meters recorded rapid tilt changes that began $10 \mathrm{~s}$ before 7:33 a.m. on June 29, 2015 (Fig. 3) and continued for $\sim 2 \mathrm{~min}$. A few hours later, a mobile observation team of the Japan Meteorological Agency (JMA) and inhabitants living approximately $1 \mathrm{~km}$ east of the eruption center observed ash fall (Mannen et al. 2018). The poor visibility in the area resulting from fog prevented the exact determination of when the eruption occurred; however, Mannen et al. (2018) argued that a phreatic eruption of Hakone volcano occurred before noon. The geophysical data supported the fact that the 


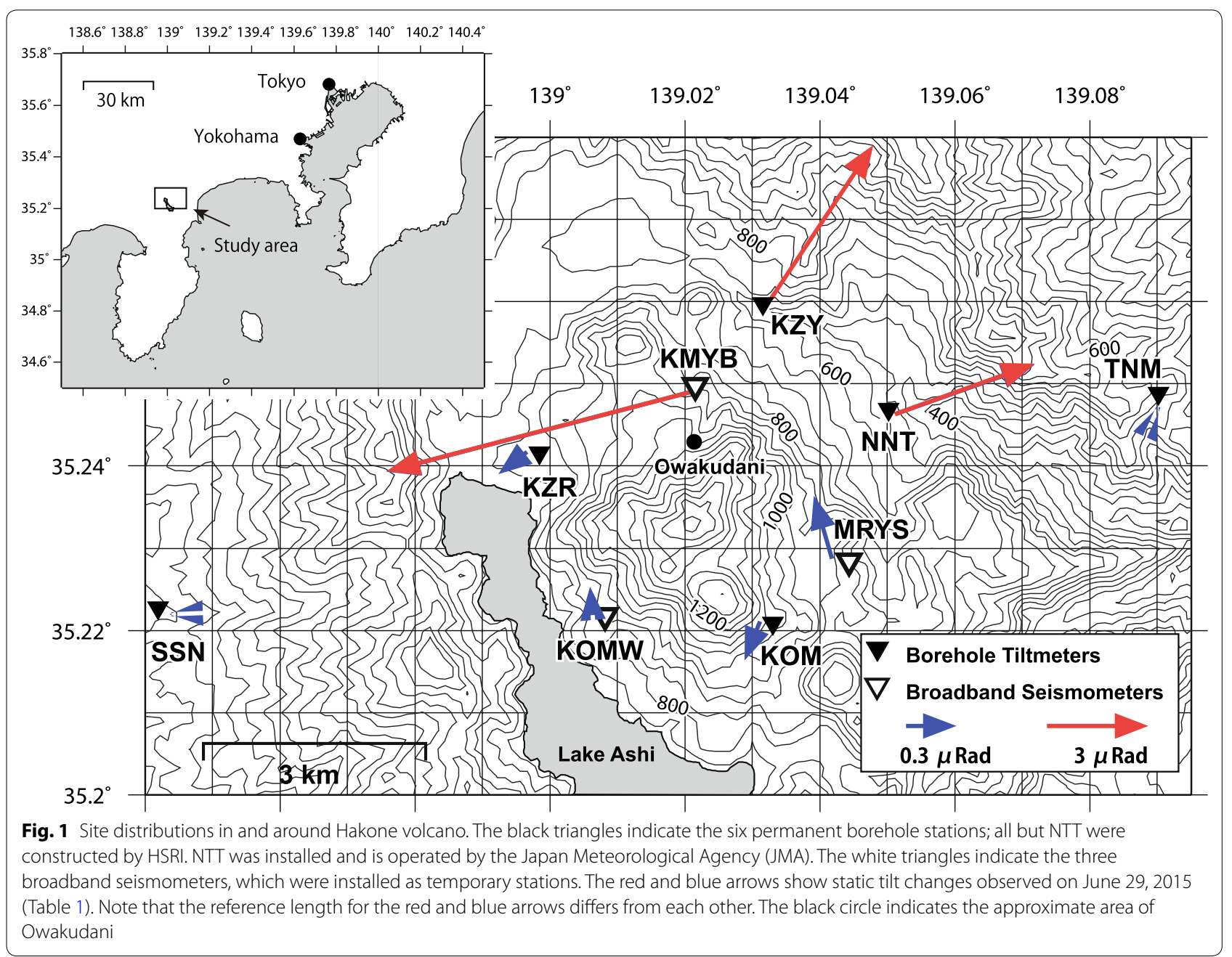

observed tilt changes were associated with phreatic eruption. For example, ground-surface uplift was observed in the area coincident to the eruption center by groundbased interferometric synthetic-aperture radar (InSAR) at nearly the same time as the rapid tilt changes (Doke et al. 2015). In addition, infrasound signals were simultaneously detected with the tilt change (Yukutake et al. 2018) and many volcanic tectonic earthquakes occurred around the central cone at the same time. Volcanic tremors were detected $\sim 3$ h later (Yukutake et al. 2017).

Seismic, geodetic, and geochemical anomalies on various timescales have been reported as precursors to eruptions (Barberi et al. 1992). Although precursor events of phreatic eruptions are difficult to detect because of the diversity of trigger mechanisms associated with these eruptions (e.g., Germanovich and Lowell 1995; Takahashi and Fujii 2014), some precursor events of phreatic eruptions have been reported. Aoyama and Oshima (2015) observed the tilt changes that occurred for $\sim 3$ min two days before a phreatic eruption of Meakan-dake volcano.
Takagi and Onizawa (2016) reported tilt changes occurring $7 \mathrm{~min}$ before the 2014 phreatic eruption of Mt. Ontake. In these cases, the tilt changes were observed by both tilt meters and broadband seismometers.

The above examples of tilt changes recorded before phreatic eruptions involved small number of observation sites, most of which were located several kilometers from the eruption center. In contrast, observation sites in Hakone volcano were distributed close to the eruption center (within several hundred meters). Thus, we were able to obtain high-quality data that can improve our understanding of the eruption process. In this paper, we use tilt-meter and broadband seismometer data indicating crustal deformation prior to the phreatic eruption to estimate a pressure source.

Tilt change during the $\mathbf{2 0 1 5}$ unrest of the Hakone volcano Long-term tilt records observed at each tilt station are shown in Fig. 2. The earthquake swarms on April 26, 2015 were accompanied by significant changes in 


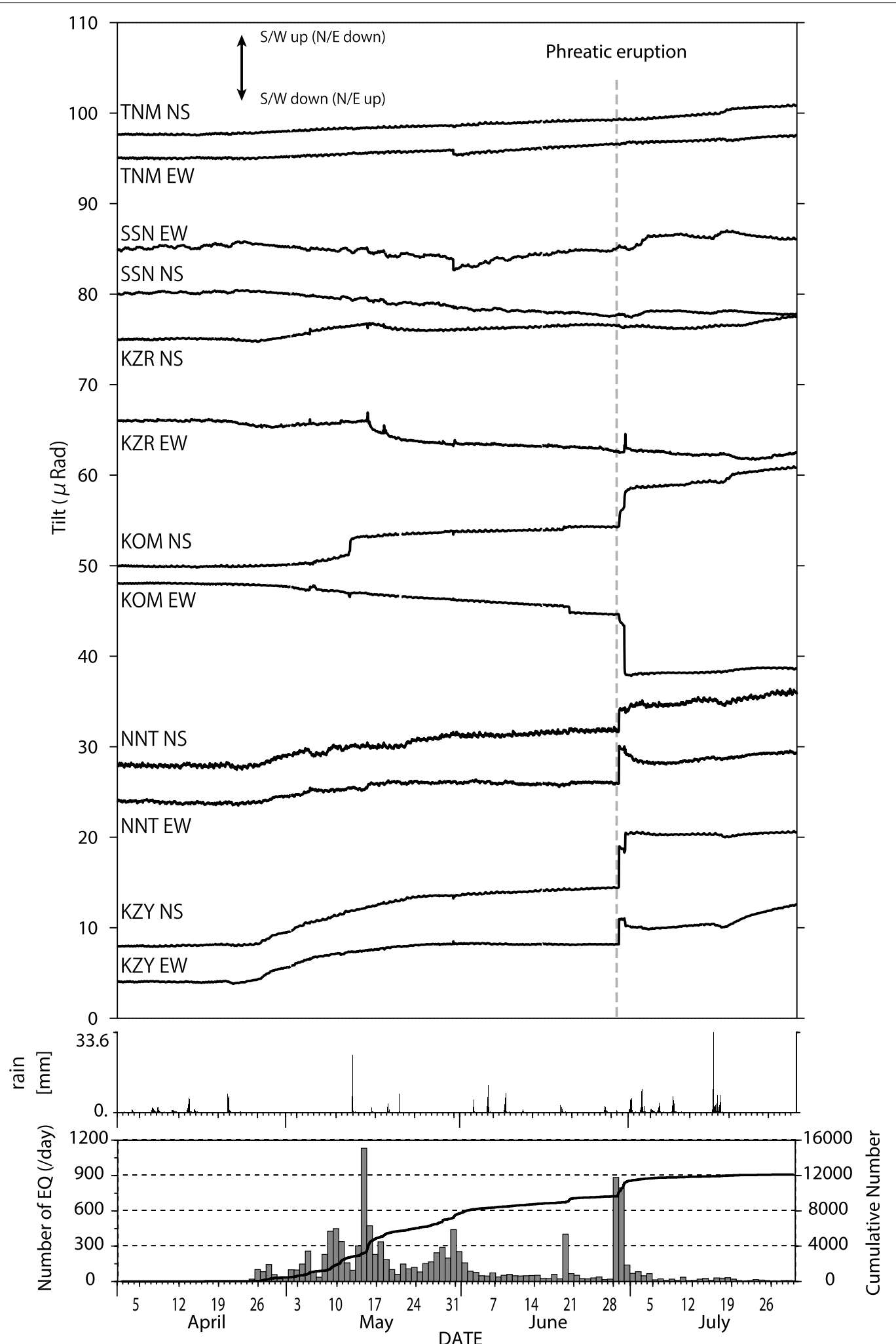

Fig. 2 Time series of tilt changes observed at the stations shown in Fig. 1. The tilt records were averaged using $1 \mathrm{~h}$ moving time window. The cumulative number of earthquakes, daily number of earthquakes, and amount of precipitation are also shown. Significant tilt changes were observed on April 26, 2015 

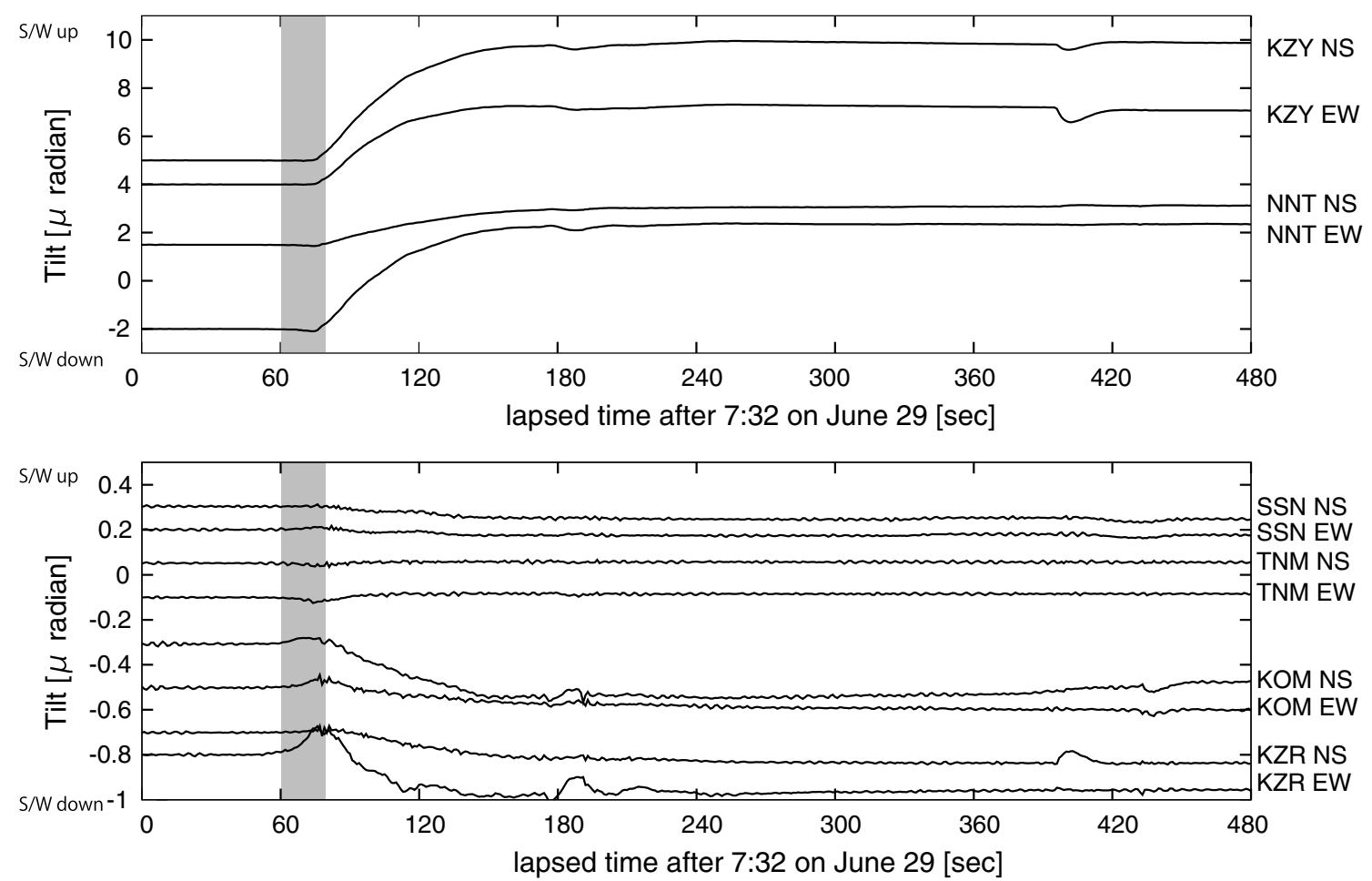

Fig. 3 Observed tilt records over an 8 min period starting at 7:32 a.m. on June 29, 2015. Note that the scale of tilt change is different for two plots. The site names and components are shown on the right-hand side of the figure. The sampling period was $1 \mathrm{~s}$. The shaded areas represent reverse motions

tilt. The tilt changes recorded at KZY (northeast direction) and at KOM (northwest direction) were similar to those observed during the 2001 unrest of Hakone volcano (Itadera and Yoshida 2015) and can presumably be explained by a source model similar to that obtained from the tilt changes during the 2001 unrest (Daita et al. 2009). In the 2015 unrest, remarkable tilt changes were observed at KZR in mid-May; the timing of these changes coincided with the activation of earthquake swarms around KZR. Based on the seismicity close to other observation sites, Itadera and Yoshida (2015) concluded that such seismicity also coincided with the tilt changes at that station. The difference in the period of high seismicity around each station suggests that not a single but plural pressure sources are responsible for the tilt motion and earthquake swarms.

Tilt changes accompanied by high seismicity have been described in many studies, and their source models, such as magma ascending through the conduit, have been suggested (e.g., Anderson et al. 2010; Neuberg et al. 2018). In these cases, the correlation between seismicity and tilt motion is much clearer and the amplitude of tilt motion is much larger than those in Hakone volcano. On the contrary, because there has been no evidence of magma ascending to the shallower part of
Hakone volcano, thin cracks filled by thermal water have likely been the pressure sources (Daita et al. 2009).

The timescales of the tilt changes discussed above range from several days to months. In contrast, the rapid tilt changes recorded just before the phreatic eruption of Hakone volcano lasted for $\sim 2$ min starting at 7:32 a.m. on June 29, 2015 (Fig. 3). This event was detected by both tilt meters and broadband seismographs, one of which was only $600 \mathrm{~m}$ from the eruption center (Fig. 4). The remainder of this paper focuses on suggesting a source model for this event, which occurred on the morning of June 29, 2015.

\section{Data}

HSRI has maintained a seismic and geodetic observation network in and around Hakone volcano since the 1960s. In 2015, we had five borehole stations equipped with tilt meters (AKASHI, JTS-33) and short-period seismometers around the central cone (Fig. 1). The tilt meters are force-balanced pendulum tilt meters with sensitivities of $20 \mathrm{mV} /$ micro rad. The outputs of the tilt meters are digitized by a 24-bit precision data converter (S501G: Meisei Electric Co., Ltd.). The final output signals (one sampling per second) are transmitted to HSRI via an optical communication network (Nippon Telegraph and Telephone 

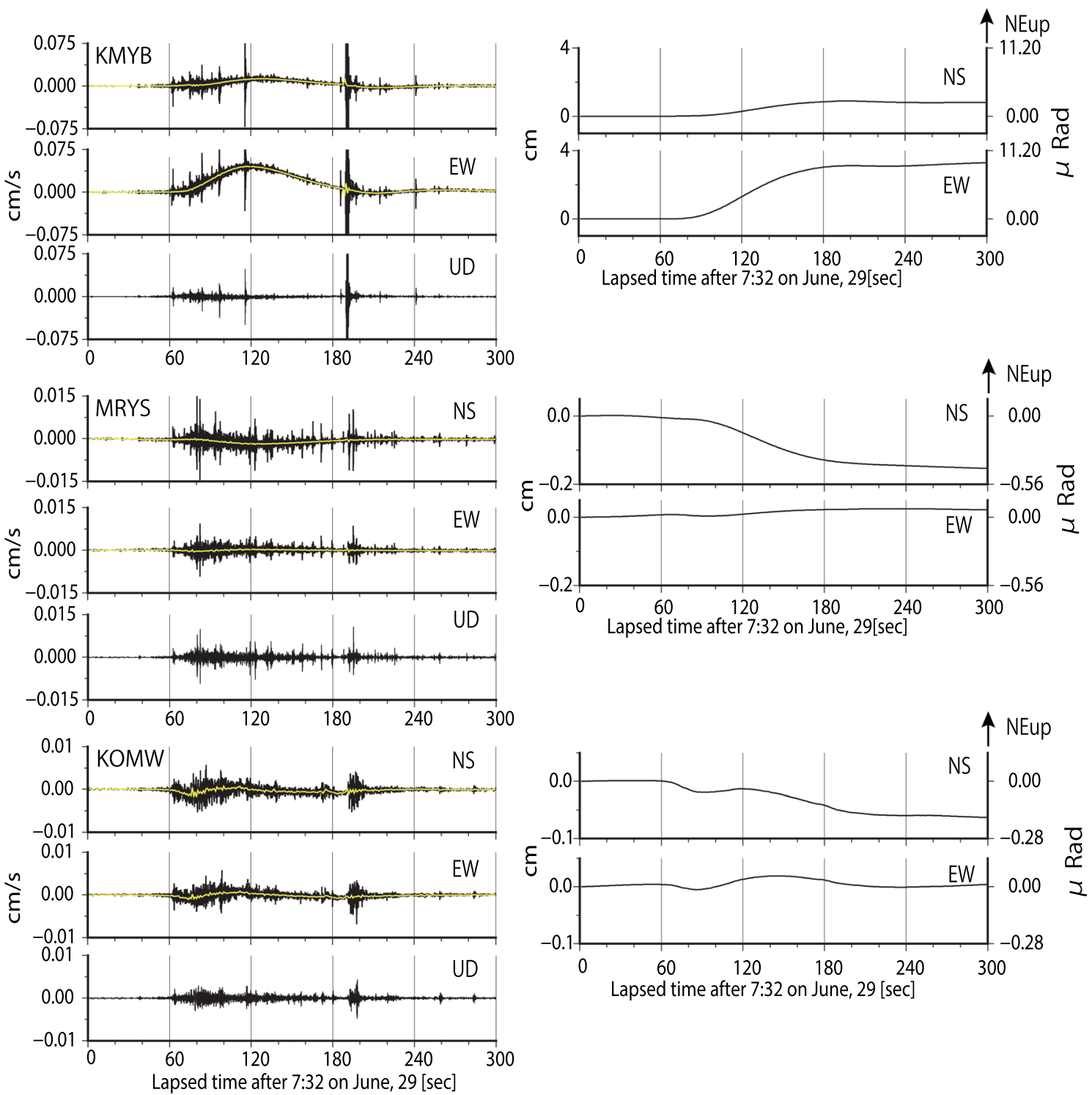

Fig. 4 Seismograms of broadband seismographs recorded on June 29, 2015. In the left column, the top, middle, and bottom three panels show the raw velocity seismograms recorded at KMYB, MRYS, and KOMW, respectively. The yellow lines on the horizontal components of the seismograms represent moving averages based on 1-s intervals. The integration records of the moving average of the horizontal components are shown in the right column. Since the integration records primarily consist of components with a period of $120 \mathrm{~s}$ or more, they are considered to represent tilt changes and are interpreted in the units on the $y$-axis right-hand side of the figure. The displacement components with periods shorter than $120 \mathrm{~s}$ are not clear and are interpreted in units on the $y$-axis on the left-hand side

East Corporation; NTT-EAST). In addition to data from the above stations, we used tilt data recorded at station $\mathrm{NNT}$ (sensitivity $=5 \mathrm{mV} / \mathrm{micro} \mathrm{rad}$ ), which is operated by JMA.

From May 20-29 during the 2015 unrest, we developed three temporary seismic stations (KMYB, KOMW, and MRYS) equipped with broadband seismometers (Trillium Compact 120S; natural period $=120$ s). These stations surrounded the central cone of Hakone volcano to monitor volcanic activity. KMYB was located on a large concrete dam, whereas KOMW and MRYS were placed on a concrete floor and a paved floor, respectively. The seismic signals were transmitted to Earthquake Research Institute (ERI) and HSRI through a mobile data communication network after digitization using $100 \mathrm{~Hz}$ sampling with a 24-bit data converter (DATAMARK LS7000XT; Hakusan Corporation). Figure 1 shows the distribution of observation sites used in this study. The tilt meters and 
broadband seismometers were used to observe the rapid tilt changes and displacement on the morning of June 29, 2015.

\section{Tilt changes on the morning on June 29, 2015 Tilt-meter records}

The tilt changes sampled at $1 \mathrm{~Hz}$ and observed between 7:32 a.m. and 7:40 a.m. on June 29, 2015 are shown in Fig. 3. The recorded tilt changes began $10 \mathrm{~s}$ before $7: 33$ am and continued for $2 \mathrm{~min}$. The static tilt changes at KZY and NNT reached $5.9 \mu \mathrm{rad}$ in the NE direction and $4.6 \mu \mathrm{rad}$ in the ENE direction, respectively. The tilt changes at the other stations were relatively small. Tilt changes in the range of $0.2-0.25 \mu \mathrm{rad}$ in SW direction were observed at KOM and KZR. The observed static tilt changes are summarized in Table 1.

Focusing on the initial part of the tilt changes (for $20 \mathrm{~s}$ from 7:33 a.m., as shown by shaded zones in Fig. 3), we can see a reverse polarity compared to the following main part (for nearly $60 \mathrm{~s}$ after the initial movements). At KZR and KOM, the initially observed eastward tilt reversed 15-20 s after their onset (Fig. 5). Similar polarity change was also observed at NNT. The southwestward tilt was observed at first, and they reversed 15-20 s after their onset. Such reverse polarity was also observed at KZY, SSN and TNM, although the amplitudes were very small. The amplitudes of the initial tilt changes were different at each station and did not depend on the amplitude of the static tilt change at the main part.

In general, force-balanced pendulum tilt meters and other types of tilt meters that detect quasi-horizontal components of gravitational acceleration also respond to horizontal displacement (short-period components of tilt). The signals from the tilt meters went through a low-pass filter (LPF) with a corner period of $30 \mathrm{~s}$ (second-order Butterworth type) and were digitized

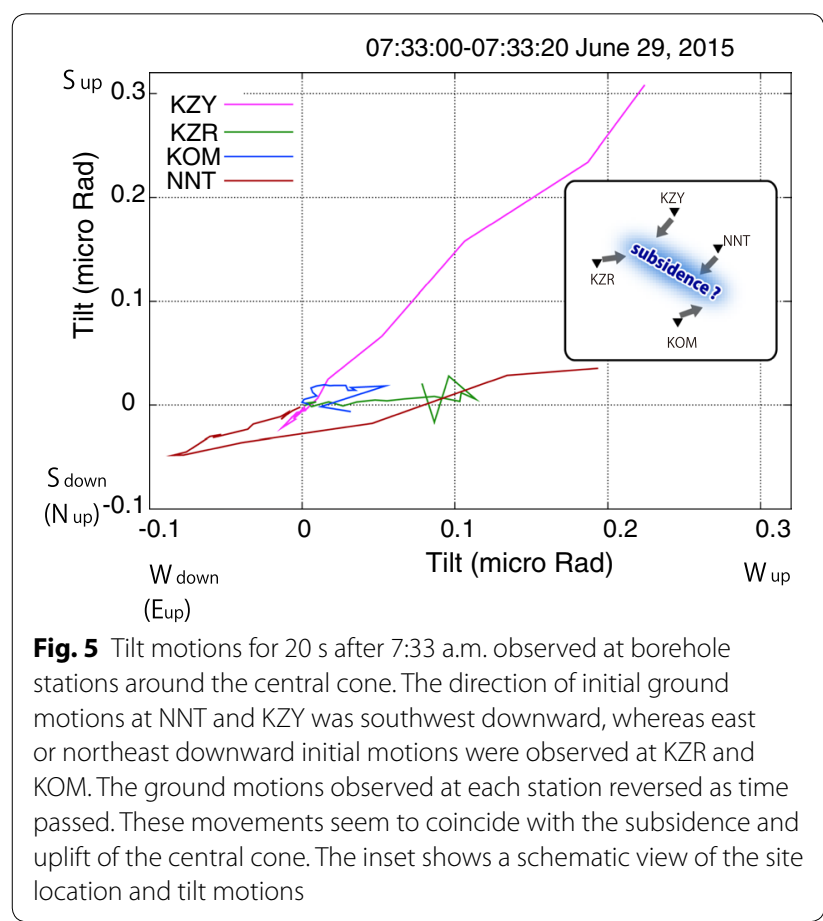

by a 24-bit A/D converter. As a result of the LPF, the response of the tilt meter to acceleration (tilt) was flat for periods longer than $30 \mathrm{~s}$, and the amplitude response for periods shorter than $30 \mathrm{~s}$ decreased in proportion to the square of the period. In other words, the amplitude response was flat for short-period displacements (Kokubo 2013). Thus, rapid horizontal displacement resulted in apparent tilt changes in the same direction as when uplift occurs in the direction of horizontal displacement (see Fig. 6, Kokubo 2013). Therefore, the tilt data acquired over a short time period required careful interpretation. The cause of these

Table 1 Tilt changes observed at each station

\begin{tabular}{|c|c|c|c|c|c|}
\hline Site name & Longitude $\left({ }^{\circ}\right)$ & Latitude $\left({ }^{\circ}\right)$ & Height $(\mathrm{m})$ & South up ( $\mu \mathrm{rad}$ ) & West up ( $\mu$ rad) \\
\hline MRYS* & 139.0437 & 35.2278 & 866 & 0.37 & -0.11 \\
\hline KMYB* & 139.0208 & 35.2490 & 885 & -2.34 & -8.98 \\
\hline $\mathrm{KOMW}^{*}$ & 139.0081 & 35.2209 & 899 & 0.17 & -0.02 \\
\hline $\mathrm{KZR}$ & 138.9985 & 35.2409 & 682 & -0.13 & -0.17 \\
\hline $\mathrm{KZY}$ & 139.0315 & 35.2589 & 451 & 4.91 & 3.27 \\
\hline KOM & 139.0330 & 35.2201 & 959 & -0.23 & -0.09 \\
\hline SSN & 138.9419 & 35.2219 & 263 & 0.00 & -0.07 \\
\hline TNM & 139.0901 & 35.2481 & 460 & 0.02 & 0.01 \\
\hline NNT & 139.0502 & 35.2460 & 452 & 1.57 & 4.35 \\
\hline
\end{tabular}

Northward and eastward tilt changes are represented by positive values. The reported static tilt changes are 1 min averages of the tilt data recorded from 7:29 to 7:30 a.m. from 7:35 to 7:36 a.m

*Broadband seismic station 


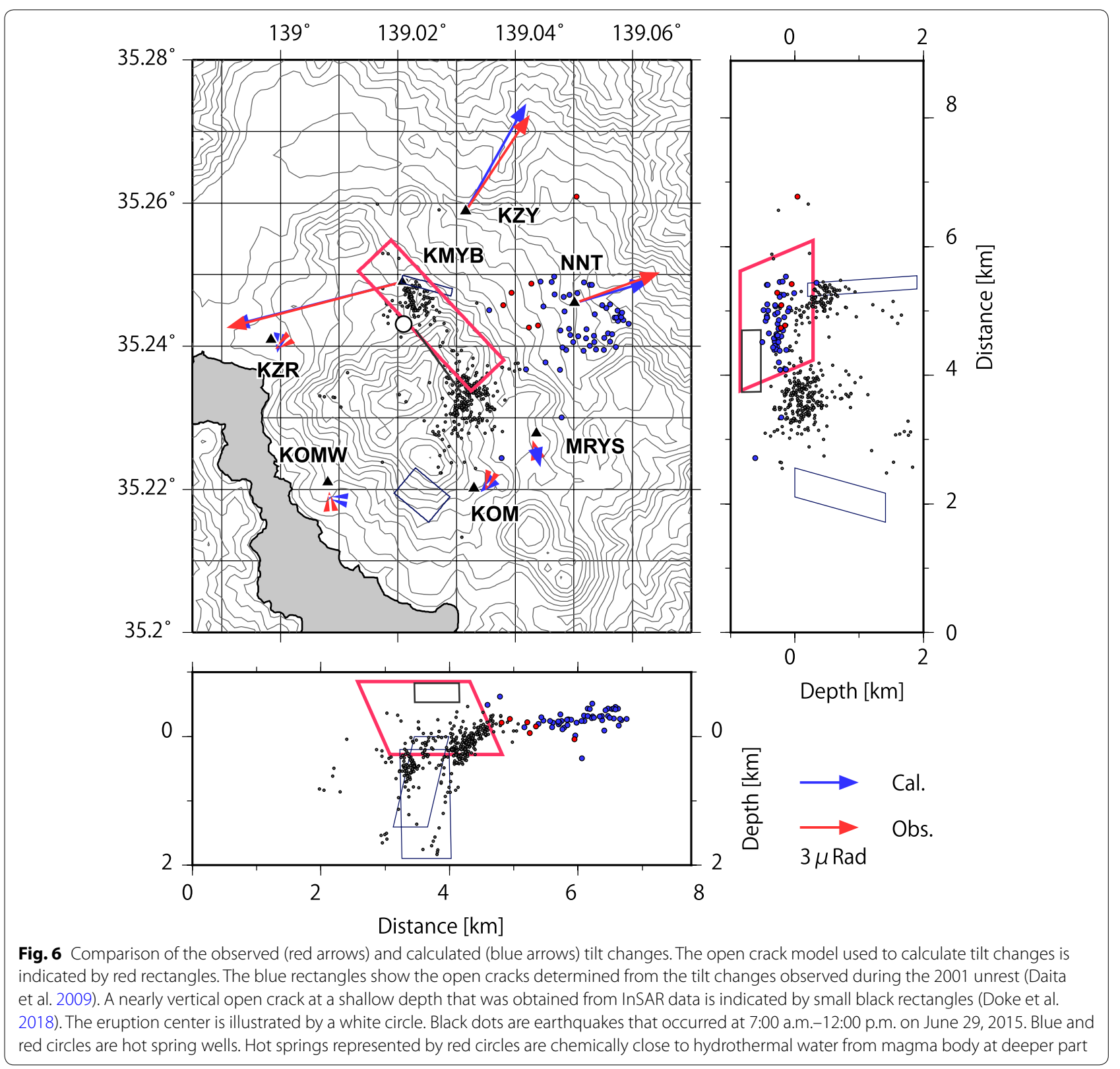

reverse polarity tilt changes described above is discussed later.

\section{Tilt-change data recorded by broadband seismometers}

The broadband seismograms recorded at the three stations are shown in Fig. 4. The amplitudes of the waveforms recorded at KMYB were much larger $(0.05 \mathrm{~cm} / \mathrm{s}$ in the EW component) than those recorded at other stations. The waveforms shown in the right column of Fig. 4 were obtained by integrating the velocity waveforms after taking the $1 \mathrm{~s}$ average. As reported by Aoyama (2008), these integrated waveforms should be interpreted as combinations of low-pass-filtered tilt motion and highpass-filtered translational displacement (cutoff period is $120 \mathrm{~s}$, the natural period of the broadband seismometer). The static component of the integrated waveforms (apparent displacement) was proportional to the amplitude of the changes in static tilt.

The static tilt changes observed by the three broadband seismometers were approximated using the proportionality constant between the static tilt change and apparent displacement. The DC component of the integrated waveform close to $4 \mathrm{~cm}$ was observed at KMYB. The proportionality constant between the static tilt change and 
Table 2 Nominal parameters for the broadband seismometer used in this study (Trillium Compact 120S)

\begin{tabular}{lll}
\hline Parameter & Nominal values & Units \\
\hline Poles $\left(p_{1}-p_{7}\right)$ & $-0.03691 \pm 0.03712 i,-371.2$, & $\mathrm{rad} / \mathrm{s}$ \\
& $-373.9 \pm 475.5 i,-588.4 \pm 1508 i$ & \\
Zeros $\left(z_{3}\right)$ & $0,0,-434.1$ & $\mathrm{rad} / \mathrm{s}$ \\
Normalization factor $k$ & $8.18 \times 10^{11}$ & $(\mathrm{rad} / \mathrm{s})^{4}$ \\
\hline
\end{tabular}

the apparent displacement for the instrument used in this study (Trillium Compact 120S) was calculated to be $3.57 \mathrm{~mm} / \mu \mathrm{rad}$ using the following expression (Aoyama 2008) with the parameters listed in Table 2 :

$$
\left.C_{T}(\omega)\right|_{\omega \rightarrow 0}=\left.\frac{g k \prod_{i=1,3}\left(i \omega-z_{i}\right)}{-\omega^{2} \prod_{j=1,7}\left(i \omega-p_{j}\right)}\right|_{\omega \rightarrow 0},
$$

where $g$ is the gravitational acceleration; $\omega$ is the angular frequency; and $\kappa, p_{i}$, and $z_{i}$ are the normalization factor, poles, and zeros, respectively, listed in Table 2. The static tilt change at KMYB was estimated to be $9.3 \mu \mathrm{rad}$ in the WSW direction. The static tilt changes for all three stations were obtained in the same way and are listed in Table 1.

\section{Pressure source model}

To obtain the source model, we estimated the static tilt changes as a result of an opening dyke in a half space (Okada 1992) and compared the changes with the observed ones. The tilt data recorded at all nine stations, including the three broadband stations, were used in the estimation of the source model (Table 1). We performed a grid search analysis for the eight parameters (longitude, latitude, height, length, width, strike, dip, and extent of crack opening) listed in Table 3 within the ranges also listed in Table 3. With the results of the grid search, we obtained the best-fit model using the least-squares method (Table 4). Figure 6 compares the observed tilt changes with those calculated using the best-fit model. The strike direction and dip angle of the best-fit model were $\mathrm{N} 316^{\circ} \mathrm{E}$ and $58^{\circ}$, respectively. The length, width, and extent of crack opening were $2555 \mathrm{~m}, 1333 \mathrm{~m}$, and $4.6 \mathrm{~cm}$, respectively. The volume change was $1.6 \times 10^{5} \mathrm{~m}^{3}$.

Figure 7 shows parameter distributions for the source models with misfits less than 3.6. Focusing on the dip and the width, source models with small misfits were distributed in a range of $45^{\circ}-67^{\circ}$ and $1066-1600 \mathrm{~m}$ for the dip and the width, respectively (Fig. 7). These results imply that the resolution in the crack expansion to depth is relatively poor in our model. This was attributed to the small tilt changes recorded at observation stations far from the crack, where contributions from the deeper part of the crack were large.

On the contrary, because misfits become greater than 3.5 for the model with the height shallower than $909 \mathrm{~m}$ above sea level, the top edge of the source is well constrained (Fig. 7). The upper corners of the observed crack of the best model reached $854 \mathrm{~m}$ above sea level, remarkably shallower than the cracks activated during the 2001 unrest (Fig. 6) (Daita et al. 2009). Since the estimated crack crossed beneath the Owakudani valley, the distance from the surface to the upper edge of the crack was minimized in the valley, approximately $150 \mathrm{~m}$ below the ground surface. This is consistent with the vents formed during the 2015 unrest, which appeared immediately above the upper edge of the crack.

Using Global Navigation Satellite System (GNSS) data collected from mid-April to July, 10 2015, Harada et al. (2015) calculated the volume change of the Mogi source at a depth of $7.5 \mathrm{~km}$ to be approximately $7.6 \times 10^{6} \mathrm{~m}^{3}$. Even when the uncertainties associated

Table 3 The parameters and corresponding ranges used in grid search analysis

\begin{tabular}{llllllll}
\hline Longitude $\left(^{\circ}\right)$ & Latitude $\left(^{\circ}\right)$ & Height $(\mathbf{m})$ & Length $(\mathbf{m})$ & Width $(\mathbf{m})$ & Dip $\left(^{\circ}\right)$ & Strike $\left(^{\circ}\right)$ & Open $(\mathbf{c m})$ \\
\hline $139.01-139.07$ & $35.20-35.29$ & $909-659$ & $1000-3000$ & $400-1600$ & $45.0-85.0$ & $200-350$ & $1-7$ \\
$(0.0075)$ & $(0.0112)$ & $(27.7)$ & $(222)$ & $(133)$ & $(4.4)$ & $(16.6)$ & $(1.2)$ \\
\hline
\end{tabular}

The step interval for each parameter is shown in parentheses

Table 4 Parameters of the best-fit model

\begin{tabular}{|c|c|c|c|c|c|c|c|}
\hline Longitude $\left({ }^{\circ}\right)$ & Latitude $\left({ }^{\circ}\right)$ & Height (m) & Length (m) & Width (m) & $\operatorname{Dip}\left({ }^{\circ}\right)$ & Strike $\left({ }^{\circ}\right)$ & Open $(\mathrm{cm})$ \\
\hline 139.0325 & 35.2338 & 854 & 2555 & 1333 & 58 & 316 & 4.6 \\
\hline
\end{tabular}

The location of the crack shown in the table is the upper south corner 

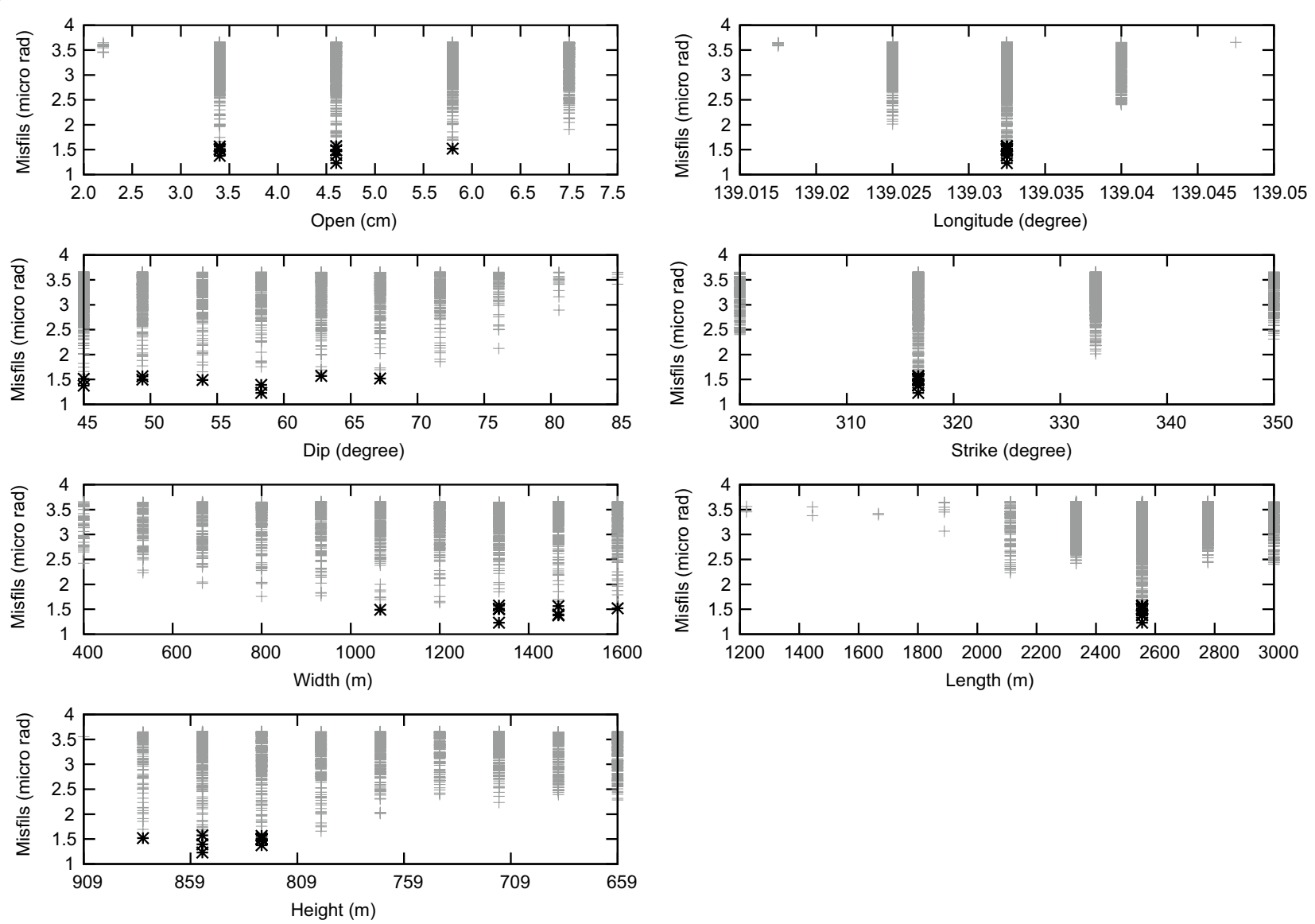

Fig. 7 Parameter distributions for the source models with misfits less than 3.6. Black asterisks indicate top 10 source models with small misfits. The resolution for height, width, and dip angle are relatively poor, indicating that the constraint of crack expansion toward depth is not good. The results for latitude are not shown because the value did not change in this range of misfits

with the length, width, and extent of crack opening were considered, the volume change obtained from GNSS data was much larger than that obtained from our model $\left(1.6 \times 10^{5} \mathrm{~m}^{3}\right)$. These data could reflect different phenomena beneath Hakone volcano.

Doke et al. (2018) obtained the pressure source model using InSAR data taken before and after the eruption. The time resolution in their analysis was several weeks, which is significantly longer than the period of our analysis, although InSAR techniques have enabled us to perform high-resolution mapping of surface deformation. Although the size of their model is smaller than that of our model, they obtained a crack model that has similar orientation and almost the same depth of the upper edge. The surface projection of the upper edge of both models was almost overlapping. Thus, the depth and geometry of our model is reasonable.

\section{Discussion}

\section{Apparent motion based on the tilt data}

As shown in Fig. 5, reverse polarity movements were recognized during the initial part of the tilt changes at 7:32 a.m. on June 29, 2015. These initial reverse polarity movements may indicate the subsidence of the mountain edifice associated with the contraction of thee shallow pressure sources, as shown by the schematic in Fig. 5. Alternatively, the initial movements could be interpreted as a response to translational motion. Here, we discuss whether the observed reverse movements reflect a source process (i.e., subsidence of the volcano before its inflation). The reverse polarity movements shown in Figs. 3 and 5 have a duration of less than $30 \mathrm{~s}$, which is in the frequency range of a response for displacement. In the following, we attempt to explain the initial tilt motions by the contamination through the displacement response of the tilt meters shown in Kokubo (2013). 
In general and in approximate single-source models of crustal deformation, it can be assumed that the tilt and translational motion at a certain point are proportional to the two horizontal components, i.e., $d_{x}(t)=C_{x} \gamma_{x}(t)$ and $d_{y}(t)=C_{y} \gamma_{y}(t)$ with respect to the horizontal displacement $\left[d_{x}(t), d_{y}(t)\right]$ and the tilt change $\left[\gamma_{x}(t), \gamma_{y}(\mathrm{t})\right]$. The proportional constants $C_{x}$ and $C_{y}$ can be obtained from the ratios of the components of displacement and tilt change calculated by the formulae reported by Okada (1992) using the best-fit model. Since the expressions for the components $x$ and $y$ are the same, the distinction is omitted hereafter, and $C$ represents $C_{x}$ and $C_{y}$ for each component described above. According to Kokubo (2013), each component of a discrete apparent tilt motion can be represented as a recurrence equation:

$$
\alpha_{n}=b_{0} \gamma_{n}+b_{1} \gamma_{n-1}+b_{2} \gamma_{n-2}-a_{1} \alpha_{n-1}-a_{2} \alpha_{n-2},
$$

where

$$
\begin{aligned}
b_{0} & =\frac{1}{a_{0}}\left(\tau^{2}+4 C / g\right)\left[m^{-3}\right], \quad b_{1}=\frac{1}{a_{0}}\left(2 \tau^{2}-8 C / g\right)\left[m^{-3}\right], \quad b_{2}=\frac{1}{a_{0}}\left(\tau^{2}+4 C / g\right)\left[m^{-3}\right], \\
a_{1} & =\frac{1}{a_{0}}\left(2 \tau^{2}-8 / \omega_{d}^{2}\right), \quad a_{2}=\frac{1}{a_{0}}\left(\tau^{2}-2 \sqrt{2} \tau / \omega_{d}+4 / \omega_{d}^{2}\right), \\
a_{0} & =\tau^{2}+2 \sqrt{2} \tau / \omega_{d}+4 / \omega_{d}^{2} \quad\left[s^{2}\right], \\
\omega_{d} & =\frac{2}{\tau} \tan ^{-1} \frac{\tau \omega_{c}}{2} \cong \frac{2 \pi}{30.1} \quad\left[s^{-1}\right],
\end{aligned}
$$
crack opening.

Note that Eq. (2) is a purely empirical function. Figure 8 compares the observed tilt records with those calculated assuming various time constants $(T)$. Even though the amplitudes of the initial tilt changes with reverse polarity motion differed at each component, most of the observed records (excluding the EW component of KZR) could be represented by the calculated records with a long time constant (e.g., 30 or 45 s). Although the approximated function shown in Eq. (2) remains to be verified, we can conclude that the observed tilt changes were caused by

Considering the EW component at KZR, the calculated amplitude of displacement response was significantly larger than the observed one. This implied that a larger displacement toward the west was expected. Such a dis-

and

$$
\omega_{c}=2 \pi / T_{c}[\mathrm{rad} / \mathrm{s}],
$$

where $\tau$ is the sampling period ( $1 \mathrm{~s}$ in this case), $\omega_{c}$ and $\omega_{d}$ are the angular frequencies in the analog and digital domains, respectively, represented by the corner period of the filter, $T_{c}(=30 \mathrm{~s})$. Assuming true tilt motion $\gamma(t)$ caused by a crack opening, the apparent tilt records can be calculated for $1-\mathrm{Hz}$ sampling using the above equations and then compared with the observed tilt records.

Kokubo (2013) demonstrated that the apparent reverse polarity attributed to the short-period component of the translational motion occurred in the tilt data using the exponential relaxation function as an example of the time function of source expansion $(\gamma(t)$ in the above equations). In this study, we expected the time function of source expansion to have a gentle onset and the duration of rapid displacement that contributed to the dominant displacement response was $\sim 20 \mathrm{~s}$ (Fig. 3). After some trial and error (Additional file 1: Fig. S1), we found that the following function minimizes the difference between the calculated and observed tilt changes (Fig. 8): crepancy between the observed and calculated data may be attributed to the existence of another pressure source, spatial heterogeneity in the amount of crack opening, and/or errors caused by topographic effects.

\section{What does the crack opening imply?}

One important question is what intruded into the shallow part of the mountain edifice and caused the crack to open. The orientation of a dyke associated with a magma intrusion is typically controlled by the axis of the maximum compressional stress $\left(\sigma_{H}\right)$ in the region (e.g., Ukawa and Tsukahara 1996; Hayashi and Morita 2003). In this study, the estimated strike direction of the pressure source model $\left(\mathrm{N} 316^{\circ} \mathrm{E}\right)$ was close to the microcrack orientation obtained by $S$-wave splitting analysis, which reflects $\sigma_{H}$ of the regional stress field (Honda et al. 2014). Using focal mechanism data, Yukutake et al. (2006) also estimated a consistent stress field around the Hakone volcano. This indicates that the orientation of the obtained open crack model is consistent with the direction of the $\sigma_{H}$ axis in the region. Therefore, the crack opening potentially reflects the intrusion of magma at depth. In fact, the 


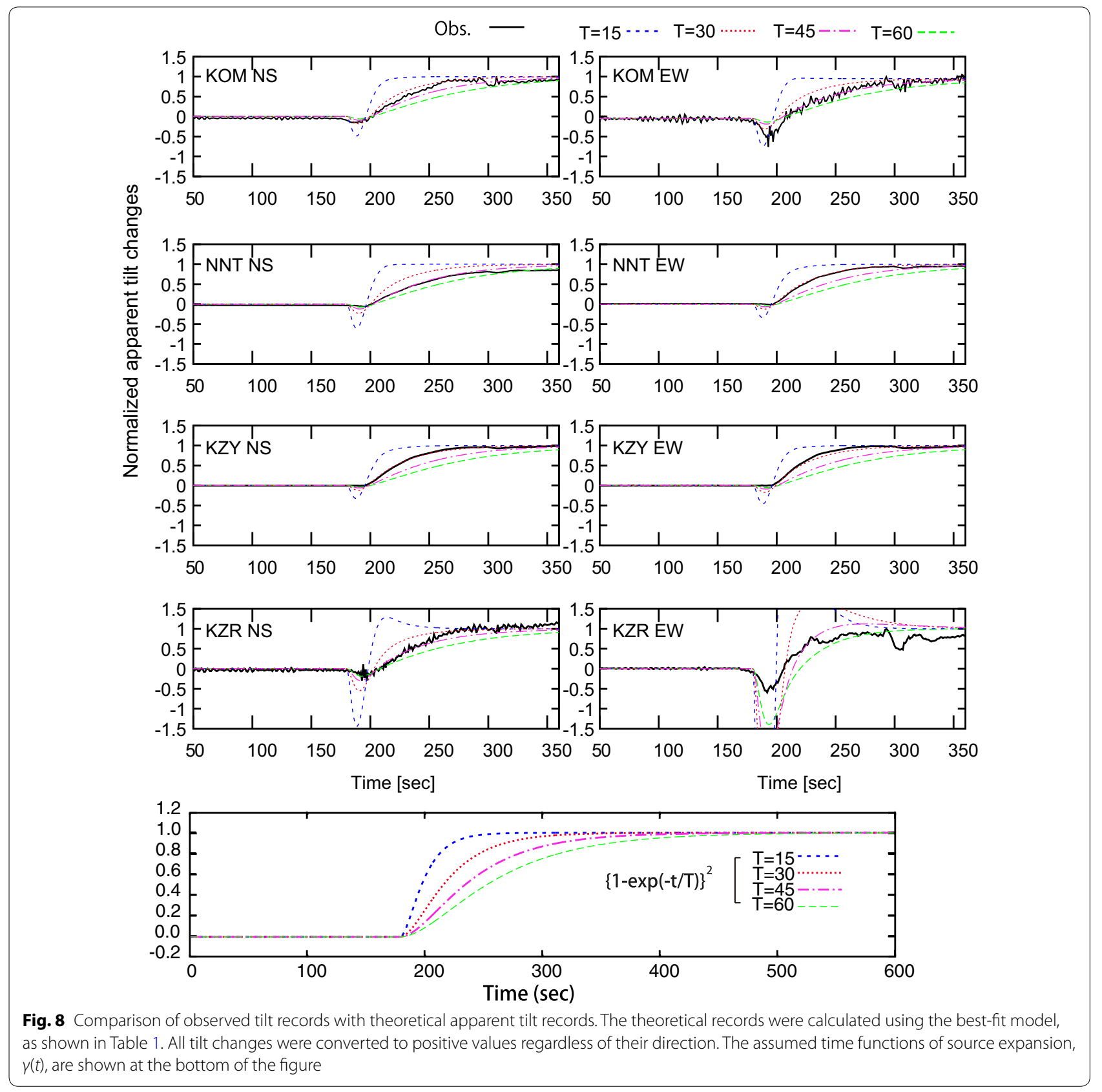

open crack orientation was the same as the average strike direction of old dykes $\left(\mathrm{N} 50^{\circ} \mathrm{W}\right)$ reported by Kuno (1964).

A dyke thickness exceeding $1 \mathrm{~m}$ is necessary for an intrusion of basaltic magma (Mege and Korme 2004); andesite intrusions, such as the intrusion expected at Hakone volcano, should form even thicker dykes. Nagai and Takahashi (2008) investigated the chemical compositions of rocks comprising Hakone volcano and found that the volcanic rocks contained $50-60 \mathrm{wt} \% \mathrm{SiO}_{2}$. According to Wada (1994), the viscosity of a magma containing
$50 \mathrm{wt} \% \mathrm{SiO}_{2}$ should be $1-3 \mathrm{~Pa} \cdot \mathrm{s}$ and requires a dyke width greater than $1 \mathrm{~m}$. This is consistent with the widths of old dykes reported for Hakone volcano (1-5 m) (Kuno 1964). These values are significantly larger than the crack thickness obtained in this study $(4.5 \mathrm{~cm})$, indicating that the crack opening was not caused by magma intrusions.

Based on seismic wave tomography, Yukutake et al. (2015) proposed a model of a magma-hydrothermal system for Hakone volcano. They found two zones of low $V p$ and low $V s$ characterized by low $V p / V s$ and high $V p / V s$ 
at depths of at 3-10 and 10-20 km beneath Hakone volcano, respectively. They interpreted the low- $V p / V s$ zone to indicate the presence of fluids and/or gas, while the high- $V p / V s$ zone was thought to correspond to a midcrustal magma body. Honda et al. (2014) reported that the anisotropic intensities from $S$-wave splitting in the shallow part of Hakone volcano are comparable with those observed near active faults. Collectively, these results suggest that the shallow part of the crust below Hakone volcano is highly fractured and may contain hydrothermal water.

Hydrological or chemical studies on hot springs and/ or volcanic gases are useful for discussing the origins of hydrothermal water in fractures in the study region (e.g., Machida et al. 2007; Kikugawa et al. 2011; Itadera et al. 2013). These past studies indicated that hot spring water in some wells originated from the magma body (red circles in Fig. 6) and that water in the other wells could be explained by a mixture of magma-originated water and groundwater. Ohba et al. (2011) investigated the coseismic changes in the chemical composition of volcanic gases at Owakudani based on the time sequence of the 2001 unrest. They proposed a schematic model for the transport of volcanic gas from the magma chamber to the surface. According to this model, degassing occurred when magma intruded into the magma chamber at a depth of 7-10 km beneath Hakone volcano. Subsequently, volcanic gas was transported to the shallow part and intruded cracks. Thus, the cracks acted as channels for volcanic gas and caused the observed tilt changes during the 2001 unrest. A pressure source model explaining the tilt changes was proposed by Daita et al. (2009) and is shown in Fig. 6.

The long-term tilt changes observed during 2015 were similar to those observed during the 2001 unrest (Itadera and Yoshida 2015), indicating that the crack activity was similar in both cases. Our crack model was obtained right above the crack model reported by Daita et al. (2009). Thus, the tilt changes observed on the morning of June 29, 2015 were interpreted as the intrusion of hydrothermal water from cracks or fractures filled by hydrothermal water at the deeper part of the mountain through preexisting cracks at the shallower part.

While the source process of the crack opening on the morning of June 29 could not be definitively determined, hydrofracturing (e.g., Nakashima 1993) is one of the candidate explanations. Since the velocity of crack propagation attributed to hydrofracturing is much lower than the rate of fault propagation in an elastic body, the source process the tilt change on June 29 might be explained by this mechanism.

\section{Topography effects}

Many studies have demonstrated that surface deformation resulting from underground pressure sources can be affected by topography (e.g., Cayol and Cornet 1998; Lungarini et al. 2005; Meo et al. 2008; Seismology and Volcanology Research Department, MRI 2008). Such topographic effects are more prominent when the observation sites are located on steep slopes (i.e., the average slope of the flanks of the volcano exceed $20^{\circ}$ ); the topographic effect cannot be ignored when the slope exceeds $30^{\circ}$. The slope of the top of the northeastern side of the central cone of Hakone volcano is approximately $25^{\circ}$ (Hattanji and Moriwaki 2011). In contrast, the slopes on which stations KZY, NNT, and KMYB are located are significantly less steep $\left(<10^{\circ}\right.$; Additional file 2 : Fig. S2). Therefore, while the observed tilt changes may have been affected by topography, topography effects were not likely essential in the estimation of the source model. As discussed earlier, the geometry and location of the best-fit model in this study do not contradict preexisting fissures, dykes, and crack models estimated based on InSAR data (Doke et al. 2015).

\section{Conclusions}

In this study, we analyzed the tilt changes near Hakone volcano on the morning of June 29, 2015 based on the data from tilt meters and broadband seismometers. Tilt changes recorded in $1 \mathrm{~Hz}$ sampling showed reverse motion with respect to the motion in the main part during the first $20 \mathrm{~s}$ after the onset. This reverse motion could be explained by the response for the translational displacement of the tilt meter. We developed a crack model based on the static tilt change recorded by the tilt meters and those estimated from broadband seismograms. The strike direction of the pressure source agreed with the direction of maximum compression in the study region. The depth of the top of the crack was located at $854 \mathrm{~m}$ above sea level. The distance from the top edge of the crack to the ground surface was minimized just below the eruption center.

Based on the findings of this study, the chronology of the phreatic eruption of Hakone volcano in 2015 can be summarized as follows. At 7:32 a.m. on June 29, 2015, surface inflation around the eruption center accompanied by tilt changes was observed by ground-based InSAR (Doke et al. 2015). Infrasonic signals were detected at almost the same time (Yukutake et al. 2018). Ash fall was reported approximately $3 \mathrm{~h}$ later at 12:45 p.m. (Mannen et al. 2018). Although the formation of a new vent was not recognized until 4:37 p.m. because of poor visibility, Mannen et al. (2018) argued that the ash fall was an 
evidence of the first phreatic eruption. The largest vent was formed on July 01, 2015 (Mannen et al. 2018), and volcanic tremors with the highest amplitudes and impulsive infrasonic waves were observed from 3:00 a.m. to 6:00 a.m. (Yukutake et al. 2017, 2018). The above reports suggest that crack opening could have been the first trigger of the phreatic eruption. The long-term tilt changes indicated that the crack activity in 2015 was similar to that during the 2001 unrest. The open crack model of the 2001 unrest was located just below the open crack estimated from the tilt changes observed on June 29, 2015. When preexisting cracks at the shallow part were connected to fractures or cracks that were filled with hydrothermal water, the cracks were forced to open, causing the tilt changes. Consequently, hydrothermal fluid was transported to the surface, resulting in phreatic eruption.

We were able to obtain high-quality data from stations deployed one month before the 2015 phreatic eruption of Hakone volcano. After the 2015 unrest, we constructed permanent observation sites equipped with biaxial bubble tilt meters, broadband seismographs, and infrasound meters around Owakudani. This high density of observation sites will allow us to collect high-quality data to improve our understanding of the eruption mechanism in the future and more closely monitor volcanic activity.

\section{Additional files}

Additional file 1. Comparison of synthetic apparent tilt motions calculated using four time functions. Examples of the time functions of source expansion are shown in the left panel. F1 [Eq. (2)] was used in this study with the time constant $T$ set to $45 \mathrm{~s}$. F2 is an exponential relaxation function represented by $1-\exp (-t / T)$ with $T$ set as $45 \mathrm{~s}$. F3 and F4 are smoothed ramp functions $\left(0.5 \times\left(1.0+\tanh \left((4.0 \times t) / T_{r}\right)\right)\right)$ with the rise time $T_{\text {r set to }} 60$ and $120 \mathrm{~s}$, respectively. The right panel shows the apparent tilt motions calculated using the functions in the left panel. The NS component of tilt change observed at KZR is indicated by the orange line.

Additional file 2. The map represents surface slope gradation. The location of the best-fit model (red rectangle), the eruption center (red circle), and tilt observation stations (white triangles) are shown in the map. Yellow arrows indicate the locations of old fissures.

\section{Abbreviations}

HSRI: Hot Springs Research Institute of Kanagawa Prefecture; InSAR: Interferometric synthetic-aperture radar; JMA: Japan Meteorological Agency; ERI: Earthquake Research Institute; GNSS: Global Navigation Satellite System.

\section{Authors' contributions}

$\mathrm{RH}$ analyzed the tilt and broadband records for a shallow pressure source and drafted the manuscript. YY, YM, and SS helped construct the temporary observation sites and monitored the seismic data. KK made considerations for displacement responses. KI analyzed long-term tilt changes. All authors read and approved the final manuscript.

\section{Author details}

${ }^{1}$ Hot Springs Research Institute of Kanagawa Prefectural Government, 586 Iriuda, Odawara, Kanagawa 250-0031, Japan. ${ }^{2}$ Earthquake Research Institute, University of Tokyo, 1-1-1 Yayoi Bunkyo-ku, Tokyo, Japan. ${ }^{3}$ Meteorological
Research Institute, Japan Meteorological Agency, 1-1, Nagamine, Tsukuba, Ibaraki 305-0052, Japan.

\section{Acknowledgements}

We thank Dr. Hiroshi Aoyama for providing the proportional constant between displacement and tilt for the broadband seismometer. We are grateful to Dr. Akimichi Takagi for his valuable comments and suggestions related to topographic effects. We thank Dr. Ryosuke Doke, who provided a base map showing the slope gradation of Hakone volcano. This article was improved through the constructive review by Dr. Stephanie Prejean and two anonymous reviewers. Most of the figures were prepared using Generic Mapping Tools (Wessel and Smith 1998). The authors would like to thank Enago (www. enago.jp) for the English language review.

\section{Competing interests}

The authors declare that they have no competing interests.

\section{Availability of data and materials}

The data used in this study are not publicly opened. Please contact author for data requests.

\section{Funding}

This study was mainly implemented as an ordinary research project of HSRI and partly supported by MEXT "Integrated Program for Next Generation Volcano Research and Human Resource Development."

\section{Publisher's Note}

Springer Nature remains neutral with regard to jurisdictional claims in published maps and institutional affiliations.

Received: 14 January 2018 Accepted: 27 June 2018

Published online: 11 July 2018

\section{References}

Anderson K, Lisowski M, Segall P (2010) Cyclic ground tilt associated with the 2004-2008 eruption of Mount St. Helens. J Geophys Res Solid Earth 115:1-29. https://doi.org/10.1029/2009JB007102

Aoyama H (2008) Simplified test on tilt response of CMG40T seismometers. Kazan 53:35-46. https://doi.org/10.18940/kazan.53.1_35 (in Japanese with English abstract)

Aoyama H, Oshima H (2015) Precursory tilt changes of small phreatic eruptions of Meakan-dake volcano, Hokkaido, Japan, in November 2008. Earth Planets Space 67:1 19. https://doi.org/10.1186/s40623-015-0289-9

Barberi F, Bertagnini A, Landi P, Principe C (1992) A review on phreatic eruptions and their precursors. J Volcanol Geotherm Res 52:231-246. https:// doi.org/10.1016/0377-0273(92)90046-G

Cayol V, Cornet H (1998) Effects of topography on the interpretation of the deformation field of prominent volcanoes: application to Etna. Geophys Res Lett 25:1979-1982

Daita Y, Tanada T, Tanbo T, Ito H, Harada M, Mannen K (2009) Temporal change of the pressure source estimated by tilt records during the 2001 Hakone swarm activity. Kazan 54:223-234. https://doi.org/10.18940/kazan 54.5223 (in Japanese with English abstract)

Doke R, Harada M, Takenaka J, Mannen K (2015) Surface deformation at Owakudani associated with 2015 volcanic activities of Hakone volcano. In: Abstract of Volcanological Society of Japan fall meeting in 2015. p 41 (in Japanese)

Doke R, Harada M, Mannen K, Itadera K, Takenaka J (2018) InSAR analysis for detecting the route of hydrothermal fluid to the surface during the 2015 phreatic eruption of Hakone Volcano, Japan. Earth Planets Space 70:63. https://doi.org/10.1186/s40623-018-0834-4

Germanovich LN, Lowell RP (1995) The mechanism of phreatic eruptions. J Geophys Res Solid Earth 100:8417-8434. https://doi.org/10.1029/94JBO 3096

Harada M, Doke R, Honda R, Yukutake Y, Itadera K, Mannen K, Takenaka J, Satomura M, Miyaoka K (2015) Crustal deformation and its deformation source associated with volcanic activities of Hakone volcano (2015). In: 
Abstract of volcanological society of Japan fall meeting in 2015, p 95 (in Japanese)

Hattanji T, Moriwaki H (2011) Topographic features and mobility of old landslides in Tanzawa and Hakone areas: focusing on equivalent coefficient of dynamic friction and areal expansion of landslide mass -. J Jpn Landslide Soc 48:45-51. https://doi.org/10.3313/jls.48.45 (in Japanese with English abstract)

Hayashi Y, Morita Y (2003) An image of a magma intrusion process inferred from precise hypocentral migrations of the earthquake swarm east of the Izu Peninsula. Geophys J Int 153:159-174. https://doi.org/10.1046/j.1365246X.2003.01892.x

Honda R, Ito H, Yukutake Y, Harada M, Yoshida A (2011) Features of hypocentral area of swarm earthquakes in Hakone volcano in 1970's revealed by re-analysis using S-P data: comparison with recent activities. KAZAN 56:1-17. https://doi.org/10.18940/kazan.56.1_1 (in Japanese with English abstract)

Honda R, Yukutake Y, Yoshida A, Harada M, Miyaoka K, Satomura M (2014) Stress-induced spatiotemporal variations in anisotropic structures beneath Hakone volcano, Japan, detected by S wave splitting: a tool for volcanic activity monitoring. Ryou J Geophys Res Solid Earth 119:70437057. https://doi.org/10.1002/2014JB010978

Itadera K, Yoshida A (2015) Correlation between ground tilts and earthquake swarms observed during the 2015 Hakone volcanic activity. Bull Hot Springs Res Inst Kanagwa Prefect 47:11-22 (in Japanese with English abstract)

Itadera K, Kikugawa G, Yoshida A (2013) Abnormal Temperature increase of thermal waters in Gora Spa of Hakone during the 1960s. J Hot Spring Sci 62:294-305 (in Japanese with English abstract)

Kikugawa G, Itadera K, Yoshida A (2011) A new classification of hot spring waters welling out in the Gora buried caldera structure, Hakone, Japan. J Hot Spring Sci 60:445-448 (in Japanese with English abstract)

Kokubo K (2013) Response of tiltmeters to volcanic crustal deformation models that include short period components. Q J Seismol 77:1-14 (in Japanese with English abstract)

Kuno H (1964) Dike swarm in Hakone volcano. Bull Volcanol 27:1-7

Lungarini L, Troise C, Meo M, De Natale G (2005) Finite element modelling of topographic effects on elastic ground deformation at Mt. Etna. J Volcanol Geotherm Res 144:257-271. https://doi.org/10.1016/j.jvolgeores .2004 .11 .031

Machida I, Itadera K, Mannen K (2007) Source area of heat and NaCl for hot springs in Gora region, Hakone. J Groundw Hydrol 49:327-339. https:// doi.org/10.5917/jagh1987.49.327

Mannen K (2003) A re-examination of Hakone earthquake swarms by literature (1917-1960): implications for the regional tectonics. Kazan 48:425-443. https://doi.org/10.18940/kazan.48.6_425 (in Japanese with English abstract)

Mannen K, Yukutake Y, Kikugawa G, Harada M, Itadera K, Takenaka J (2018) Chronology of the 2015 eruption of Hakone volcano, Japan: geological background, mechanism of volcanic unrest and disaster mitigation measures during the crisis. Earth Planets Space 70:68. https://doi.org/10.1186/ s40623-018-0844-2

Mege D, Korme T (2004) Dyke swarm emplacement in the Ethiopian Large Igneous Province: not only a matter of stress 132:283-310. https://doi. org/10.1016/S0377-0273(03)00318-4

Meo M, Tammaro U, Capuano P (2008) Influence of topography on ground deformation at Mt. Vesuvius (Italy) by finite element modelling. Int $J$ Non Linear Mech 43:178-186. https://doi.org/10.1016/j.jjnonlinme c.2007.12.005
Nagai M, Takahashi M (2008) Geology and eruptive history of Hakone Volcano, Central Japan. Res Rep Kanagawa Prefect Mus Nat Hist 13:25-42 (in Japanese)

Nakashima Y (1993) Static stability and propagation of a fluid-filled edge crack in rock: implication for fluid transport in magmatism and metamorphism. J Phys Earth 41:189-202. https://doi.org/10.4294/jpe1952.41.189

Neuberg JW, Collinson ASD, Mothes PA, Ruiz MC (2018) Understanding cyclic seismicity and ground deformation patterns at volcanoes: intriguing lessons from Tungurahua volcano, Ecuador. Earth Planet Sci Lett 482:193200. https://doi.org/10.1016/j.epsl.2017.10.050

Ohba T, Daita Y, Sawa T, Taira N, Kakuage Y (2011) Coseismic changes in the chemical composition of volcanic gases from the Owakudani geothermal area on Hakone volcano, Japan. Bull Volcanol 73:457-469. https://doi. org/10.1007/s00445-010-0445-9

Okada Y (1992) Internal deformation due to shear and tensile faults in a halfspace. Bull Seismol Soc Am 82:1018-1040

Seismology and Volcanology Research Department, MRI (2008) Studies on evaluation method of volcanic activity. Tech Rep Meteorol Res Inst 53:1-303 (in Japanese)

Takagi A, Onizawa S (2016) Shallow pressure sources associated with the 2007 and 2014 phreatic eruptions of Mt. Ontake, Japan. Earth Planets Space 68:135. https://doi.org/10.1186/s40623-016-0515-0

Takahashi K, Fujii I (2014) Long-term thermal activity revealed by magnetic measurements at Kusatsu-Shirane volcano, Japan. J Volcanol Geotherm Res 285:180-194. https://doi.org/10.1016/j.jvolgeores.2014.08.014

Ukawa M, Tsukahara H (1996) Earthquake swarms and dike intrusions off the east coast of Izu Peninsula, central Japan. Tectonophysics 253:285-303. https://doi.org/10.1016/0040-1951(95)00077-1

Wessel P, Smith WHF (1998) New, improved version of generic mapping tools released. EOS Trans Am Geophys Union 79:579. https://doi. org/10.1029/98EO00426

Yukutake Y, Tanada T, Honda R, Ito H, Harada M (2006) The determination of focal mechanisms in the region of western Kanagawa. Bull Hot Springs Res Inst Kanagwa Prefect 38:69-76

Yukutake Y, Tanada T, Honda R, Harada M, Ito H, Yoshida A (2010) Fine fracture structures in the geothermal region of Hakone volcano, revealed by wellresolved earthquake hypocenters and focal mechanisms. Tectonophysics 489:104-118. https://doi.org/10.1016/j.tecto.2010.04.012

Yukutake Y, Honda R, Harada M, Arai R, Matsubara M (2015) A magma-hydrothermal system beneath Hakone volcano, central Japan, revealed by highly resolved velocity structures. J Geophys Res Solid Earth 120:32933308. https://doi.org/10.1002/2014/JB011856

Yukutake Y, Ueno T, Miyaoka K (2016) Determination of temporal changes in seismic velocity caused by volcanic activity in and around Hakone volcano, central Japan, using ambient seismic noise records. Prog Earth Planet Sci 3:29. https://doi.org/10.1186/s40645-016-0106-5

Yukutake Y, Honda R, Harada M, Doke R, Saito T, Ueno T, Sakai S, Morita Y (2017) Continuous volcanic tremor during the 2015 phreatic eruption in Hakone volcano. Earth Planets Space. https://doi.org/10.1186/s40623-017-0751-y

Yukutake Y, Ichihara M, Honda R (2018) Infrasonic wave accompanying a crack opening during the 2015 Hakone eruption. Earth Planets Space 70:53. https://doi.org/10.1186/s40623-018-0820-x

\section{Submit your manuscript to a SpringerOpen ${ }^{\odot}$ journal and benefit from:}

- Convenient online submission

- Rigorous peer review

- Open access: articles freely available online

- High visibility within the field

- Retaining the copyright to your article

Submit your next manuscript at $\boldsymbol{\nabla}$ springeropen.com 